\title{
Analytical tools for monitoring changes in physical and chemical properties of chromatography resin upon reuse
}

\author{
Mili Pathak ${ }^{1}$, Katherine Lintern ${ }^{3}$, Thomas F. Johnson ${ }^{3}$, Aswathy M. Nair ${ }^{2}$, Soumyo Mukherji ${ }^{2}$, Daniel G. \\ Bracewell $^{3}$, Anurag S. Rathore ${ }^{1 *}$ \\ ${ }^{1}$ Department of Chemical Engineering, Indian Institute of Technology, New Delhi, India. \\ ${ }^{2}$ Department of Biosciences and Bioengineering, Indian Institute of Technology, Bombay, India. \\ ${ }^{3}$ Department of Biochemical Engineering, University College London, London, United Kingdom
}

*Corresponding author:

Anurag Rathore

Professor, Department of Chemical Engineering

Indian Institute of Technology

Hauz Khas, New Delhi, 110016, India

Phone: +91-9650770650

Email: asrathore@biotechcmz.com

Web: www.biotechcmz.com 


\begin{abstract}
Protein A chromatography is currently the method of choice for efficient and selective capture of monoclonal antibodies. Protein A resin is one of the most expensive raw materials that is used in antibody purification and as a result it is common practice to reuse the resin for multiple cycles to improve process economy. As the resin is reused, decreases in binding capacity and product recovery are typically observed due to the presence of unwanted materials, referred to as foulants. Several methods are presently used for monitoring resin fouling in Protein A chromatography. In this paper, we have used a wide spectrum of qualitative and quantitative analytical methods and compared them with respect to their ability to analyze and characterize fouled protein A resin. Six analytical tools, namely particle size analysis, HPLC, fluorescence, scanning electron microscopy, mass spectrophotometry and Fourier transform infrared (FTIR) spectroscopy are examined in this study. The tools are compared with respect to their strengths and shortcomings in terms of their capability for detecting foulant presence and relating to chromatographic cycle performance. While the focus of this paper is on fouling of protein A chromatography resin, the results are pertinent to any mode of chromatography.
\end{abstract}

Key words: Protein A chromatography, column reuse, fluorescence, microscopy. 


\section{Introduction}

Monoclonal antibodies (mAbs) have great potential for treatment of chronic diseases, cancer, and other life-threatening diseases due to their high specificity [1], with biotherapeutics produced in large quantities using mammalian cell culture in controlled bioreactors [2, 3].

Protein A chromatography is established as the capture step in purification platforms used for production of monoclonal antibody therapeutics [4-8]. This mode of chromatography has been successfully employed over the decades to purify antibodies from a variety of sources including mammalian cell culture and transgenic plants. One of the long recognized challenges with the Protein A ligand has been its limited stability under strongly alkaline conditions that are routinely used in clean-in-place (CIP) procedures for chromatography columns [9-15]. As a result, regeneration of Protein A chromatography columns is typically carried out using high concentrations of chaotropic agents such as urea or guanidine hydrochloride, sometimes at acidic pH. Researchers have reported that limited exposure to mild alkaline conditions can be successfully employed for regeneration of Protein A resins [9-15]. More recently, resin manufacturers have attempted to engineer the Protein A ligand so as to improve its alkaline tolerance and this has resulted in launch of products such as MabSelect $\mathrm{SuRe}^{\mathrm{TM}}$ and most recently PrismA ${ }^{\mathrm{TM}}$ that is marketed on improved alkaline stability [16-18]. Despite the significant advancements that industry has made in design of Protein A chromatography materials, what has remained unchanged is that Protein A resins are the largest contributors to the cost of manufacturing and as a result, manufacturing processes economically necessitate reuse of resin. A recent survey of users of Protein A chromatography report that while most manufacturers desire to obtain 100-200 reuses for this resin, typical achievable usage ranges from 50-100 cycles [19]. In a protein A chromatography process, after product elution has been 
accomplished the resin is subjected to a strip condition to remove any residual product and impurities from the column prior to its regeneration (CIP). There are numerous factors that can cause variability in performance of a Protein A chromatography step (Table 1), including variation in the elution, strip, and regeneration procedures and in the composition of the feed material (concentration of product, lipids, host cell proteins, nucleic acids, and cell culture media constituents) $[20,21]$. The latter is particularly significant as the Protein A column is used as a capture step and as a result faces a feed that consists of a myriad of impurities. Given the complexity of this step, an improved understanding of fouling of Protein A resin would be critical for improving lifetime. As the incoming feed material from upstream manufacturing consists of complex mixture of components including target product, impurities, and unwanted cell metabolites, feed composition is likely to significantly impact resin clearance capacity by reducing binding capacities and altering process kinetics. In extreme cases, it may lead to failure of batches due to unacceptable compromises in product safety and efficacy. For this reason, online monitoring and control is critical to ensure that the process operates within defined limits and that product quality consistently meets specifications.

At present, a variety of analytical tools are used for qualitative and quantitative characterization of fouled resin. These include UV spectroscopy, high pressure liquid chromatography (HPLC), microscopy and mass spectroscopy. However, each of the tools suffers from certain disadvantages most notably of which is the fact that most of these tools are amenable to be used for off line analysis. This would require the user to withdraw a sample of fouled resin from the column and then perform offline testing, something that cannot be done during commercial production of a biotherapeutic due to the practicalities of sampling a packed bed. 
This paper presents the data obtained from a variety of analytical tools for performing qualitative and quantitative characterization of physical and chemical properties of fouled resins. Six analytical tools, namely particle size analysis, HPLC, fluorescence, scanning electron microscopy, mass spectrophotometry and Fourier transform infrared (FTIR) spectroscopy were examined in this study, including comparisons with respect to their strengths and shortcomings.

\section{Materials and methods}

\subsection{Materials and equipment}

Human IgG 4 monoclonal antibody (mAb) with isoelectric point 7.3 and molecular weight $\sim 150$ $\mathrm{KD}$, expressed in Chinese Hamster Ovary (CHO) cells, was donated by a major domestic manufacturer of biosimilars. The feed material consisted of clarified harvest with product

concentration of 4-6 mg.ml ${ }^{-1}$. All chromatographic experiments were carried out on an Äkta Purifier (GE Healthcare, Uppsala Sweden) chromatographic system. This system has built-in $\mathrm{UV}, \mathrm{pH}$, and conductivity detectors to monitor the effluent from the chromatographic experiments. Empty Tricorn glass columns with $0.5 \mathrm{~cm}$ I.D. and $20 \mathrm{~cm}$ length were procured from GE Healthcare Life Sciences (Uppsala, Sweden). MabSelect SuRe resin was also procured from GE Healthcare. An Environmental Scanning Electron Microscope (FEI Quanta 200) Netherlands was used high resolution imaging of chromatography beads in various states. FTIR analysis were performed using 3000 Hyperion Microscope with Vertex 80 FTIR spectrometer at ambient conditions in absorbance mode. LC-MS/MS was performed using C18 Acclaim

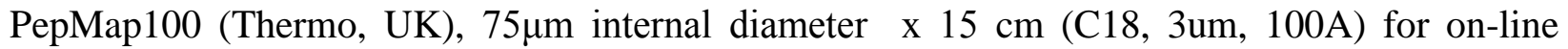
reverse phase HPLC (Nano LC Ultimate3000, Thermo UK). LC was coupled to a fraction 
collector (ProteineerfcII, Bruker, Coventry, UK). MALDI-TOF-TOF was conducted using an UltrafleXtreme MALDI-TOF instrument (Bruker, Coventry, UK).

Sodium chloride, sodium dihydrogen phosphate, and disodium hydrogen phosphate buffer salts were purchased from Merck, India. For preparative chromatography, analytical grade chemicals were used and for analytical chromatography, HPLC grade chemicals were used. Blue dextran was purchased from GE Healthcare Life Sciences (Uppsala, Sweden).

\subsection{Scale down model for resin cycling}

The Protein A chromatography step was scaled down as per our previously published protocol [11]. The column was equilibrated with a $25 \mathrm{mM}$ Phosphate, $50 \mathrm{mM} \mathrm{NaCl}$ at $\mathrm{pH} 6.2$ buffer. Post equilibration, a minimum of five $\mathrm{CV}$ of equilibration buffer was passed through the column. This was followed by loading of the clarified cell culture broth (CCCB) at a loading capacity of 15 $\mathrm{mg} \cdot \mathrm{ml}^{-1}$ of resin. Elution was performed using $100 \mathrm{mM}$ acetate, $\mathrm{pH} 3.5$ buffer, and was followed by regeneration with $2 \mathrm{M} \mathrm{NaCl}$ and cleaning with $50 \mathrm{mM} \mathrm{NaOH}, 1 \mathrm{M} \mathrm{NaCl}$ (contact time kept to less than 15 minutes). The mobile phase velocity was $200 \mathrm{~cm} / \mathrm{h}$ and cleaning was performed after every three cycles.

A single cycle consisted of the following steps: milli-Q wash, equilibration, loading, washing, elution, and stripping. Cleaning was performed after every third cycle. In the case of cycling studies without feed material, all steps were followed except the loading step. Robustness of the scale down model was established by performing 40 cycles in duplicates as per the protocol defined above. Similarly, resin cycling studies with and without product loading were performed using the protocol mentioned above.

\subsection{Estimation of dynamic binding capacity}


DBC at $10 \%$ of the breakthrough curve was determined for the fresh resin (before starting cycling studies on the column) and after every 10 cycles. Purified mAb was used to determine DBC [20].

\subsection{LC-MS/MS analysis}

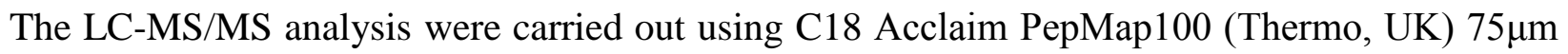
internal diameter $\times 15 \mathrm{~cm}(\mathrm{C} 18,3 \mathrm{um}, 100 \mathrm{~A})$ reverse phase HPLC column (Nano LC Ultimate3000, Thermo UK) using our previously published protocol [22]. MALDI-TOF-TOF was conducted using an UltrafleXtreme MALDI-TOF instrument (Bruker, Coventry, UK) in positive ion reflector mode and 50\% laser power and MS-MS was conducted on the ten most intense peaks for each target spot [22].

\subsection{Estimation of mass transport parameters}

Inter-particle porosity $\left(\varepsilon_{p}=V_{D e x} / V_{c o l}\right)$ was determined by performing $100 \mu \mathrm{L}$ pulse injections of 3 mg.ml ${ }^{-1}$ blue dextran solution (molecular weight of $2 \times 10^{6} \mathrm{Da}$ ). Further, a pulse injection of 100 $\mathrm{uL}$ of $1 \mathrm{M} \mathrm{NaCl}$ was used to determine the total porosity. The intraparticle porosity $\left(\varepsilon_{i}=\left(\mathrm{NaCl}^{-}\right.\right.$ $\left.\left.V_{D e x}\right) /\left(V_{c o l}-V_{D e x}\right)\right)$ was calculated from these two values [20].

\subsection{Electron microscopy imaging}

Resin samples were rinsed twice in distilled water before fixing with $20 \%$ glutaraldehyde for 20 minutes, followed by two further water rinses and staining with $1 \%$ osmium tetroxide for 20 minutes. Resin samples were then dehydrated through an incremental 0-100\% ethanol gradient in preparation for critical point drying, which was performed using a E3100 chamber dryer (Quorum Technologies). Once completely dry, resin beads were transferred to carbon coated stubs and gold coated with an ion beam coater (Gatan Model 681, Oxford, UK) at $6 \mathrm{~mA}$ and an acceleration voltage of $10 \mathrm{keV}$ to a thickness of 3-5 nm. Images were obtained using a FEI 
QUANTA 200F field emission scanning electron microscope (FEI, Thermo Fisher Scientific). Parameters for image acquisition were $2 \mathrm{kV}$ accelerating voltage and 14.2.0 $\mu \mathrm{A}$, with a working distance of $6.7 \mathrm{~mm}$.

Resin sample preparation and imaging were performed for fresh and fouled resin sample at the end of $50^{\text {th }}$ cycle using our previously published protocol. Images were obtained using a Jeol JSM-7401F field emission scanning electron microscope (Jeol Ltd, Tokyo, Japan). Parameters for image acquisition were $2 \mathrm{kV}$ accelerating voltage and $5.0 \mu \mathrm{A}$, with a working distance of 5 $\mathrm{mm}$.

The surface characterization of the fresh and fouled resin samples after 50 and 100 cycles were performed using the Environmental Scanning Electron Microscope (FEI Quanta 200, Netherlands). These images help to observe the changes in the resin surface due to degradation, shrinkage or deposition while reusing them during repetitive purification cycles. The sample preparation for ESEM imaging involves the spreading of liquid resin samples in $100 \%$ ethanol on the steps with carbon tapes. Then the samples on steps were heated for 5 minutes using an IR heater. Periodic heating and cooling was done to avoid damage to resins while heating. It was then followed by coating the samples on steps with platinum at $240 \mathrm{sec}, 10 \mathrm{~mA}$. This minimizes charging effects of the sample while imaging that causes unwanted streaking artefacts.

\subsection{FTIR analysis}

FTIR characterization of fresh and fouled resin samples was performed using 3000 Hyperion Microscope with Vertex 80 FTIR spectrometer at ambient conditions in absorbance mode. Resin slurry was dried at $35^{\circ} \mathrm{C}$ and the powdered resins were mixed with potassium bromide (KBr) to form a pellet which was then subjected to FTIR imaging.

\subsection{Particle size analysis}


Particle size distributions for fresh and fouled resin were determined using a Mastersizer particle size analyzer from Bio-Rad (California, USA).

\subsection{Fluorescence analysis}

The resins were monitored online for foulant deposition during chromatographic separation. The column excitation and emission was recorded at $250 \mathrm{~nm}$ to $500 \mathrm{~nm}$ as a spectra. The light emitted by the light source was transferred to the slit and polarizer through the excitation monochromator, where the slit and polarizer transmits light of a predefined wavelength. The predefined wavelength emitted by the emission monochromator was passed through the black sheet of the column packed with resin thereby resulting in the recording of fluorescence intensity by the detector. The fluorescence intensity was recorded at every cycle and the deposition of foulants was estimated by subtracting the reading obtained for the freshly packed column with fresh chromatographic resin. The increase in the amount of fluorescence intensity at the end of respective cycles estimated the deposition of foulants on the resin over reuse [23, 24].

\section{Results and discussion}

This investigation was targeted to understand the physical and chemical changes that occur during cycling of protein A chromatography resin due to use of buffer and feed material using various analytical tools. For this purpose, cycling studies were performed using the MabSelect SuRe resin $(15 \mathrm{~cm} \times 0.5 \mathrm{~cm})$ up to a hundred cycles with and without feed material. The changes in the physical and chemical properties of Mabselect SuRe resin with and without loading feed material were monitored.

\subsection{Quantitative methods to estimate resin fouling}


Chemical properties of the Mabselect SuRe resin determine its functional properties. MabSelect SuRe consists of an engineered Protein A ligand with homotetramer-Z domain, where a number of asparagine residues have been replaced to eliminate interactions with the variable region; thereby reducing the binding heterogeneity between antibodies and allowing the resin to be able to withstand stronger alkaline conditions. Binding of mAb to the protein A ligand occurs at the Fc region at the junction between the $\mathrm{CH} 2$ and $\mathrm{CH} 3$ domains. A histidyl residue in the centre of the protein A - binding site of $\operatorname{IgG}$ comprises of four domains, each of which consists of an antiparallel three - helix bundle motif with two interhelical loops [17]. This residue aligns with a complementary and similarly conserved histidyl residue on Protein A. The interaction is favored at alkaline $\mathrm{pH}$, where the imidazolium rings remain uncharged, thereby contributing to net hydrophobicity at the interface between protein A ligand and $\mathrm{IgG}$ Fc region and strengthening the interaction. At low $\mathrm{pH}$, as in the elution steps of chromatographic processing, these histidyl residues are fully charged, hydrophilic, and mutually repellent [17]. The damage to resin can occur in various ways such as ligand loss due to degradation or leaching of protein A ligand, ligand occludence due to foulants present in the feed material or strong binding of $\mathrm{mAb}$ to ligand, non-specific interaction of foulants leading to its deposition with increasing number of cycles and base matrix damage (Figure 1) [20].

\section{Figure 1 here}

Conventional manufacturing practices involve assessment of chromatographic performance loss via monitoring of attributes like yield, dynamic binding capacity, impurities, chromatographic profile, product purity and HETP, of which yield is given the highest weightage [21]. All the above mentioned attributes serve as an indirect means of monitoring resin fouling as all of these include monitoring of eluate at the outlet of chromatography column. 
3.1.1. Yield and dynamic binding capacity: Table 2 represents the yield and DBC for fresh resin, $100^{\text {th }}$ cycle resin without load, $50^{\text {th }}$ and $100^{\text {th }}$ cycle resin with loading the feed material. It is seen that the $\mathrm{DBC}_{10 \%}$ decreases upon resin reuse with use of feed material. The decrease in capacity is greater at the end of $100^{\text {th }}$ cycle in case of the resin recycled with feed material $\left(\mathrm{DBC}_{10 \%}\right.$ at end of $100^{\text {th }}$ cycle was $20 \%$ ) as compared to the one cycles without feed material $\left(\mathrm{DBC}_{10 \%}\right.$ at end of $100^{\text {th }}$ cycle was $\left.85 \%\right)$. The yield decreases upon resin reuse due to use of feed material, where both yield and DBC are indirect measures of resin fouling.

3.1.2. Interparticle and intraparticle porosity: The interparticle porosity remains unchanged for fresh and fouled resin, but a significant change was observed for the intraparticle porosity. The interparticle porosity is comparable for fresh resin and fouled resin cycled without feed material at the $100^{\text {th }}$ cycle, while the intraparticle porosity decreases by $8.5 \%$ at the end of $50^{\text {th }}$ cycle followed by a further decrease of $30 \%$ at the end of $100^{\text {th }}$ cycle in case of resin cycled with feed material.

3.1.3. Fourier transform infrared spectroscopy (FTIR): Fresh and fouled resin samples were analyzed by FTIR using the protocol mentioned in section 2.7. Figure 2 represents the absorbance spectra for fresh and fouled resin. The bands at $1064 \mathrm{~cm}^{-1}$ are due to $\mathrm{C}-\mathrm{O}$ stretching/C-O-H bending from hydroxyl functions and at 1378, 1186 and $1149 \mathrm{~cm}^{-1}$ from polysaccharide skeletal modes [25]. The infrared absorption of Protein A with the expected amide bands peaking at 1653,1546 and $1251 \mathrm{~cm}^{-1}$. The maximum amide I absorption at 1653 $\mathrm{cm}^{-1}$ indicates a predominantly helical conformation. Polysaccharide peaks are known to overlap the protein side chain vibration modes between 1500 and $1300 \mathrm{~cm}^{-1}$ and the amide III band but do not show any interference above $1500 \mathrm{~cm}^{-1}$. The peak intensity at $1653 \mathrm{~cm}^{-1}$ decreases upon resin reuse, which indicate depletion of protein A ligand from the resin overtime. Also the 
intensity below $1500 \mathrm{~cm}^{-1}$ decreases with resin reuse indicating damage to the base matrix (polysaccharide skeleton) or unavailability (or occupancy) of functional groups due to foulant deposition.

\section{Figure 2 here}

3.1.4. Fluorescence spectroscopy: Recombinant protein A contains tyrosine and phenylalanine residues but lacks tryptophan. In contrast, tryptophan is present in common foulants (host cell proteins and $\mathrm{mAb}$ ), along with tyrosine and phenylalanine. Thus, the fluorescence intensity at $340 \mathrm{~nm}$ (Lambda max for tryptophan) is primarily due to foulants present on the resin, while the fluorescence intensity at $303 \mathrm{~nm}$ (Lambda max for tyrosine) is due to the protein A ligand present on the resin as this is dominant species. Figure 3 presents the spectra for fresh and fouled resin sample. The fresh resin sample and the fouled resin sample at $100^{\text {th }}$ cycle without loading the feed material has the lambda max at $303 \mathrm{~nm}$. The intensity at $303 \mathrm{~nm}$ in the latter case decreased, indicating ligand leaching due to the use of processing buffers. The $50^{\text {th }}$ and $100^{\text {th }}$ cycle fouled resin samples subjected to feed material cycling exhibited shift in the Lambda max to $340 \mathrm{~nm}$. The intensity at $340 \mathrm{~nm}$ for $50^{\text {th }}$ cycle resin was lesser than that for the $100^{\text {th }}$ cycle resin. This finding is in agreement with the LC-MS/MS analysis data in Figure 6.

\section{Figure 3 here}

\subsection{Qualitative methods to estimate resin fouling}

Upon resin reuse, the base matrix may get damaged thereby generating fines and degrading the crosslinked structure or there may be deposition of foulants thereby blocking the porous structure of resin. To understand the changes in physical properties of resin upon reuse, particle size estimation, TEM and SEM imaging were performed on fresh and fouled resin samples. Also LC- 
MS/MS analysis was performed for the fouled resin samples to study the presence of foulant on the resin upon reuse.

3.2.1. Particle size distribution: The average particle size $\left(\mathrm{d}_{50 \mathrm{v}}\right)$ of MabSelect $\mathrm{SuRe}$ resin is $85 \mu \mathrm{m}$. It is made up of highly cross-linked agarose matrix linked to the modified protein A ligand through epoxy linkage. The average particle size distribution for fresh and fouled resin is presented in Table 2. It is evident that with increase in number of reuses, the change in particle size for both the cases (cycling with and without feed material) is not significant.

3.2.2. Electron microscopy: Figure 4 presents TEM images for fresh resin (A, stained) and fouled resin samples (B, C and D, unstained). It was observed that in all images the uniform light grey areas are the embedding material while the darker grey is the backbone of the MabSelect SuRe resin, where dark areas are visible in the cycled resin samples. The fouled resin sample cycled using feed material from the $50^{\text {th }}$ cycle (Figure 4B) shows presence of foulants with the size of globules $<0.1 \mu \mathrm{m}$. On the other hand, fouled resin sample from the $100^{\text {th }}$ cycle (Figure 4C) exhibits deposition of foulants with a film thickness of $0.3 \mu \mathrm{m}$. The extent of fouling is greater in the fouled resin sample from the $100^{\text {th }}$ cycle than the one from the $50^{\text {th }}$ cycle. Apart from this, the fouled resin sample cycled without feed material at $100^{\text {th }}$ cycle (Figure 4D) is comparable to the fresh resin sample. Presence of few fine depositions in Figure 4D may be due to the deposition of purified IgG used for DBC estimation, which is in agreement with the LC-MS/MS data.

\section{Figure 4 here}

SEM analysis for fresh and fouled resin sample are presented in Figure 5. SEM images are presented at two different magnification of 2000X and 60000X highlighting the wholesome resin particle and the closer view of crosslinked agarose strand. Figures 5A and 5D represent electron micrographs where feed has not been in contact with the resin before imaging, with entirely fresh 
resin and up to 100 cycled counterparts without feed were found to visually be comparable in terms of surface structure, although potentially thicker fibers were observed for the cycled samples which may have been attributed to the use of purified $\operatorname{IgG}$ at every $10^{\text {th }}$ cycle to calculate binding capacity. Figures $5 \mathrm{~B}, 5 \mathrm{C}, 5 \mathrm{E}$ and $5 \mathrm{H}$ represent the images of fouled resin sample $\left(50^{\text {th }}\right.$ and $100^{\text {th }}$ cycle $)$ cycled using feed material. The fouling intensity was identified as higher at $100^{\text {th }}$ cycle that $50^{\text {th }}$ cycle with the presence of globular deposits over the agarose strand. While comparing fresh and fouled resin with and without feed material cycling it is seen that the presence of foulant deposition follows the increasing order as fresh $<$ fouled resin at $\left(100^{\text {th }}\right.$ cycle $)$ cycles without feed material $<$ fouled resin cycled with feed material at the $50^{\text {th }}$ cycle $<$ fouled resin cycled with feed material the $100^{\text {th }}$ cycle.

\section{Figure 5 here}

From the data presented here, it is clear that buffers do not cause significant physical damage to the resin during its life time as compared to the feed material. Use of feed material causes deposition of foulants on resin over time thereby reducing the intra-particle porosity.

3.1.3. Mass spectrometry: LC-MS/MS analyses were performed on the $50^{\text {th }}$ and $100^{\text {th }}$ cycle fouled resin samples subjected to feed material cycling and $100^{\text {th }}$ cycle resin sample which was devoid of feed material loading as per the protocol mentioned in section 2.4. The RP-HPLC chromatogram presented in Figure 6A shows higher peak area for $100^{\text {th }}$ cycle resin cycled with feed material followed by $50^{\text {th }}$ cycle resin cycled with feed material followed by $100^{\text {th }}$ cycle resin cycles without feed material. The MS-MS analysis for the resin digests showed higher number of proteins for the sample subjected to feed material cycling in Figure 6B. 


\subsection{Real time measurement of resin fouling}

Underperformance of a Protein A resin over reuse is known to impact the efficacy of the chromatographic resin [19]. It has been observed by several researchers that the performance attributes of chromatographic stationary phases such as step yield, host-cell-impurity clearance capability and DNA-clearance capability are likely to degrade over time [9]. High alkaline stability of MabSelect SuRe resin makes it a potential candidate for its use in manufacturing, but still the maximum number of cycle currently achieved with this resin is $50-100$ cycles. The major reason for this performance loss and short life span of MabSelect SuRe resin is the foulant deposition over resin reuse. In view of this, there is a need to continuously monitor performance of a chromatography column during manufacturing so as to be able to anticipate any performance gaps and take appropriate action to avoid performance loss using relevant tools.

The time required for all the aforementioned tools to measure the performance loss and the feasibility of its online monitoring is highlighted in Table 3. Among the different tools, fluorescence is the only one that can be used for online monitoring of resin fouling. In a previous publication [23], we have described the detailed protocol and setup to measure resin fouling upon reuse. When performing numerous subsequent cycles in column mode, there can be a gradual buildup of contaminants on the chromatography resin, causing fouling. In the study, the performance loss during chromatographic runs was measured in terms of yield and $\mathrm{DBC}_{10 \%}$. Resin samples were withdrawn from the column every 10 cycles and fluorescence intensity was monitored. Figure 7A presents the yield, DBC, and fluorescence data at different cycle numbers. It was observed that as the fluorescence intensity at $340 \mathrm{~nm}$ increases, the yield and DBC decrease thereby indicating buildup of foulants on the resin surface during reuse. This was again confirmed by the LC-MS/MS analysis of the fouled resin at the end of the $50^{\text {th }}$ cycle. An 
empirical correlation was created between fluorescence intensity and yield. This correlation was validated by performing an experiment at small scale and monitoring the fluorescence intensity online at $340 \mathrm{~nm}$ to predict yield. Figure 7B represents the predicted and experimental yield data for different cycles, with the error in prediction being $<3 \%$.

\section{Conclusions}

At the heart of initiatives such as Quality by Design $(\mathrm{QbD})$ is the desire to more completely understand the processes used to manufacture biological products and thereby develop more robust approaches to their design and control. Given their complexity, this will always be a daunting challenge, although the high costs associated with ubiquitous stages such as Protein A make understanding and improving these steps worthwhile. Logically it therefore makes sense to isolate those parameters in a unit operation that have the greatest influence, for example $\mathrm{pH}$ during cell culture. However, it is typically found such parameters interact with other parameters such as the carbon source in the cell culture in our example. The A-Mab case study [38] goes into great depth to think through those parameters likely to be of importance in the context of monoclonal antibody processing. Statistical experimental design has been shown to be a powerful tool to explore and quantify these interactions which can be enhanced by having the correct evaluative measures present throughout a process. Going the next step to understand the mechanisms giving rise to such behavior with any degree of certainty requires both a good description of the engineering science underlying the operation and appropriate analytical tools to measure the behavior of challenging cell-based systems. By better using established methods of Protein A monitoring and combining them with emerging approaches in the field such as high resolution imaging, then eventual improvements of resin re-use could approach desired levels and therefore considerably drive down Protein A costs. 


\section{References}

1. Reichert JM. Which are the antibodies to watch in 2013? MAbs. 2013;5:1-4.

2. Malik NN. Controlling the cost of innovative cancer therapeutics. Nat Rev Clin Oncol. $2009 ; 6: 550-552$

3. Kelley B. Very large scale monoclonal antibody purification: the case for conventional unit operations. Biotechnol Prog 2007;23:995-1008.

4. Sofer G. Establishing resin lifetime: key issues and regulatory positions. BioProcess Int. 2003;1:64-69.

5. Rathore AS, Sofer G. (Ed.), Process validation in manufacturing of biopharmaceuticals, third ed., CRC press, 2012.

6. Shukla AA, Hubbard B, Tressel T, Guhan S, Low D. Downstream processing of monoclonal antibodies_-application of platform approaches. J Chromatogr B. 2007;848:28-39.

7. Ghose S, McNerney T, Hubbard B. Protein A Affinity Chromatography for Capture and Purification of Monoclonal Antibodies and Fc-Fusion Proteins: Practical Considerations for Process Development, in: Shukla AA, Gadam S, Etzel M, (Ed.), Process Scale Bioseparations for the Biopharmaceutical Industry, second ed., Taylor and Francis, Florida 2007, pp. 463490.

8. Godfrey MA, Kwasowski P, Clift R, Marks V. Assessment of the suitability of commercially available SpA affinity solid phases for the purification of murine monoclonal antibodies at process scale. J Immunol Methods. 1993;160:97-105.

9. Hale G, Drumm A, Harrison P, Phillips J. Repeated cleaning of protein A affinity column with sodium hydroxide. J Immunol Methods. 1994;171:5-21. 
10. Tejeda-Mansir A, Espinoza R, Montesinos RM, Guzma R. Modelling regeneration effects on protein A affinity chromatography. Bioprocess Eng. 1997;17:39-44.

11. Gagnon, P. Purification Tools for Monoclonal Antibodies, second ed., Validated Biosystems Inc.1996.

12. Fahrner R, Blank G, Zapata G. Expanded bed protein A affinity chromatography of a recombinant humanized monoclonal antibody: process development, operation, and comparison with a packed bed method. J Biotechnol 1999;75:273-280.

13. Johansson HJ, Bergenstråhle A, Rodrigo G, Öberg K. The use of $\mathrm{NaOH}$ for CIP of rProteinA media: a 300 cycle study. In Poster presented at the ACS Conference, Boston, MA 1998.

14. Yan Z, Huang J. Cleaning procedure for protein G affinity columns. J Immunol Methods. 2000;237:203-205.

15. Linhult M, Gülich S, Gräslund T, Simon A, Karlsson M, Sjöberg A, Karin N, Hober S. Improving the tolerance of a protein a analogue to repeated alkaline exposures using a bypass mutagenesis approach. Proteins: Struct Funct Bioinf. 2004;55:407-416.

16. Hahn R, Shimahara K, Steindl F, Jungbauer A. Comparison of protein A affinity sorbents III, Life time study. J Chromatogr A. 2006;1102:224-231.

17. Hober S, Nord K, Linhult M. Protein A chromatography for antibody purification. J Chromatogr B. 2007;848:40-47.

18. Ghose S, Allen M, Hubbard B, Brooks C, Cramer SM. Antibody variable region interactions with Protein A: Implications for the development of generic purification processes. Biotechnol Bioeng 2005;92:665-673. 
19. Jiang C, Liu J, Rubacha M, Shukla AA. A mechanistic study of Protein A chromatography resin lifetime. J Chromatogr A. 2009;1216:5849-5855.

20. Pathak M, Rathore AS. Mechanistic understanding of fouling of protein A chromatography resin. J Chromatogr A. 2016;1459:78-88.

21. Rathore AS, Pathak M, Guijun M, Bracewell DG. Re-use of Protein A Resin: Fouling and Economics. Biopharm Int. 2015;28:28-33

22. Rathore AS, Pathak M, Chopda V. "Method for monitoring of foulants present on chromatographic resins using fluorescence probe”, Indian Patent Application 201611015421 (provisional), 2016.

23. Pathak M, Lintern K, Chopda V, Bracewell DG, Rathore AS. Fluorescence based real time monitoring of fouling in process chromatography. Sci Rep. 2017;7:1-8

24. Gronberg A, Eriksson M, Ersoy M, Johansson HJ. A tool for increasing the lifetime of chromatography resins. Mabs.2011;3:192-202.

25. Boulet-Audet M, Byrne B, Kazarian SG. Cleaning-in-place of immunoaffinity resins monitored by in situ ATR-FTIR spectroscopy. Anal Bioanal Chem. 2015;407:7111-7122.

26. Hahn R, Schlegel R, Jungbauer A. Comparison of protein A affinity sorbents. J Chromatogr B. 2003;790:35-51.

27. Tarrant RDR, Velez-Suberbie ML, Tait AS, Smales CM, Bracewell DG. Host cell protein adsorption characteristics during protein a chromatography. Biotechnol Prog. 2012;28:10371044.

28. Flatman S, Alam I, Gerard J, and Mussa N. Process analytics for purification of monoclonal antibodies. J Chromatogr B.2007;848:79-87. 
29. Hansen R, Dickson AJ, Goodacre R, Stephens GM, Sellick CA. Rapid characterization of $\mathrm{N}$-linked glycans from secreted and gel-purified monoclonal antibodies using MALDI-ToF mass spectrometry. Biotechnol Bioeng. 2010;107:902-908.

30. Lintern K, Pathak M, Smales CM, Howland K, Rathore AS, Bracewell DG. Residual on Column Host Cell Protein Analysis during Lifetime Studies of Protein A Chromatography. J Chromatogr A. 2016;1461:70-77.

31. Zhang S, Xu K, Daniels W, Salm J, Glynn J, Martin J, Gallo C, Godavarti R, Carta G. Structural and functional characteristics of virgin and fouled protein A MabSelect resin cycled in a monoclonal antibody purification process. Biotechnol Bioeng. 2016;113:367-375.

32. Close EJ, Salm JR, Iskra T, Sorensen E, Bracewell DG. Fouling of an Anion Exchange Chromatography Operation in a Monoclonal Antibody Process: Visualization and Kinetic Studies. Biotechnol Bioeng. 2013;110:2425-2435.

33. Zhang S, Daniels W, Salm J, Glynn J, Martin J, Gallo C, Godavarti R, Carta G. Nature of foulants and fouling mechanism in the Protein A MabSelect resin cycled in a monoclonal antibody purification process. Biotechnol Bioeng. 2016;113:141-149.

34. Shapiro MS, Haswell SJ, Lye GJ, Bracewell DG. Microfluidic Chromatography for Early Stage Evaluation of Biopharmaceutical Binding and Separation Conditions. Sep Sci Technol. 2011;46:185-194.

35. Holland D, Sederman A, Mantle M, Gladden L, Middelberg A. Quantitative magnetic resonance imaging of urea and lysozyme in protein chromatography. J Chromatogr A. 2004;1033:311-319.

36. Astrath DU, Lottes F, Vu DT, Arlt W, Stenby EH. Experimental investigation of liquid chromatography columns by means of computed tomography. Adsorption. 2007;13:9-19. 
37. Boulet-Audet M, Kazarian SG, Byrne B. In-column ATR-FTIR spectroscopy to monitor affinity chromatography purification of monoclonal antibodies. Sci Rep. 2016;6:1-13.

38. The A-Mab case study.

https://cdn.ymaws.com/www.casss.org/resource/resmgr/imported/A-

Mab_Case_Study_Version_2-1.pdf 


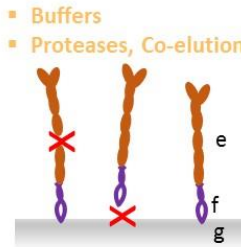

Ligand loss

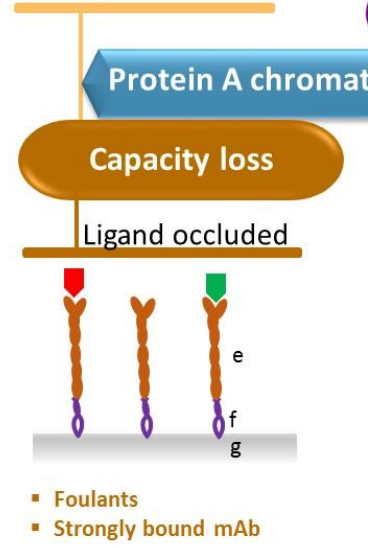

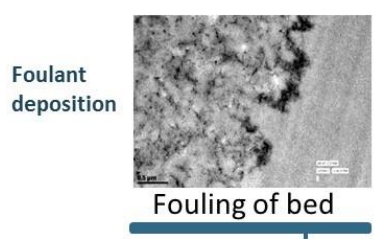

Packed bed failure

Figure 1: Different phenomena occurring during protein A chromatography resin fouling.

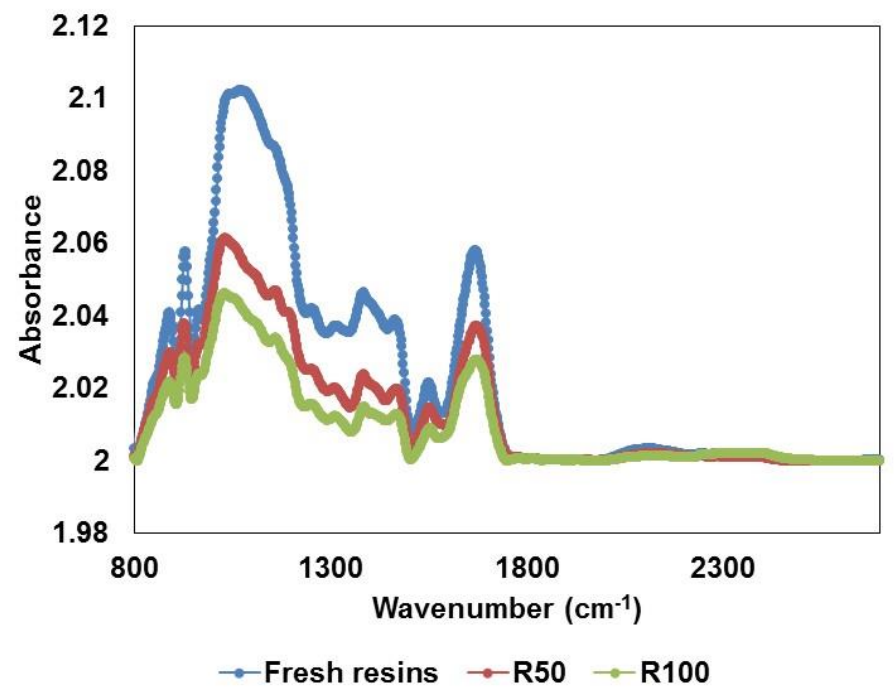

Figure 2: FTIR analysis for fresh and fouled resin samples. 


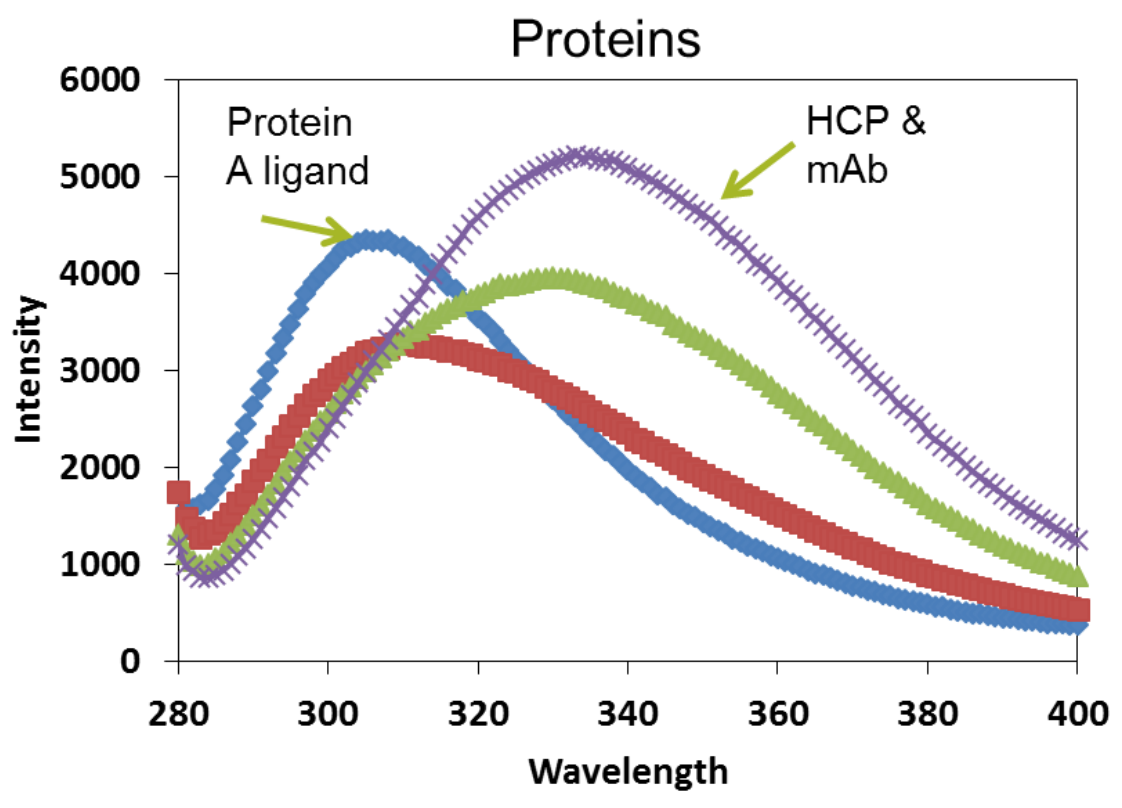

$\neg-$ Fresh $\rightarrow-$ Effect of buffer $\leftarrow 50$ cycles $\leftarrow 100$ cycles

Figure 3: Fluorescence spectroscopy analysis for fresh and fouled resins.
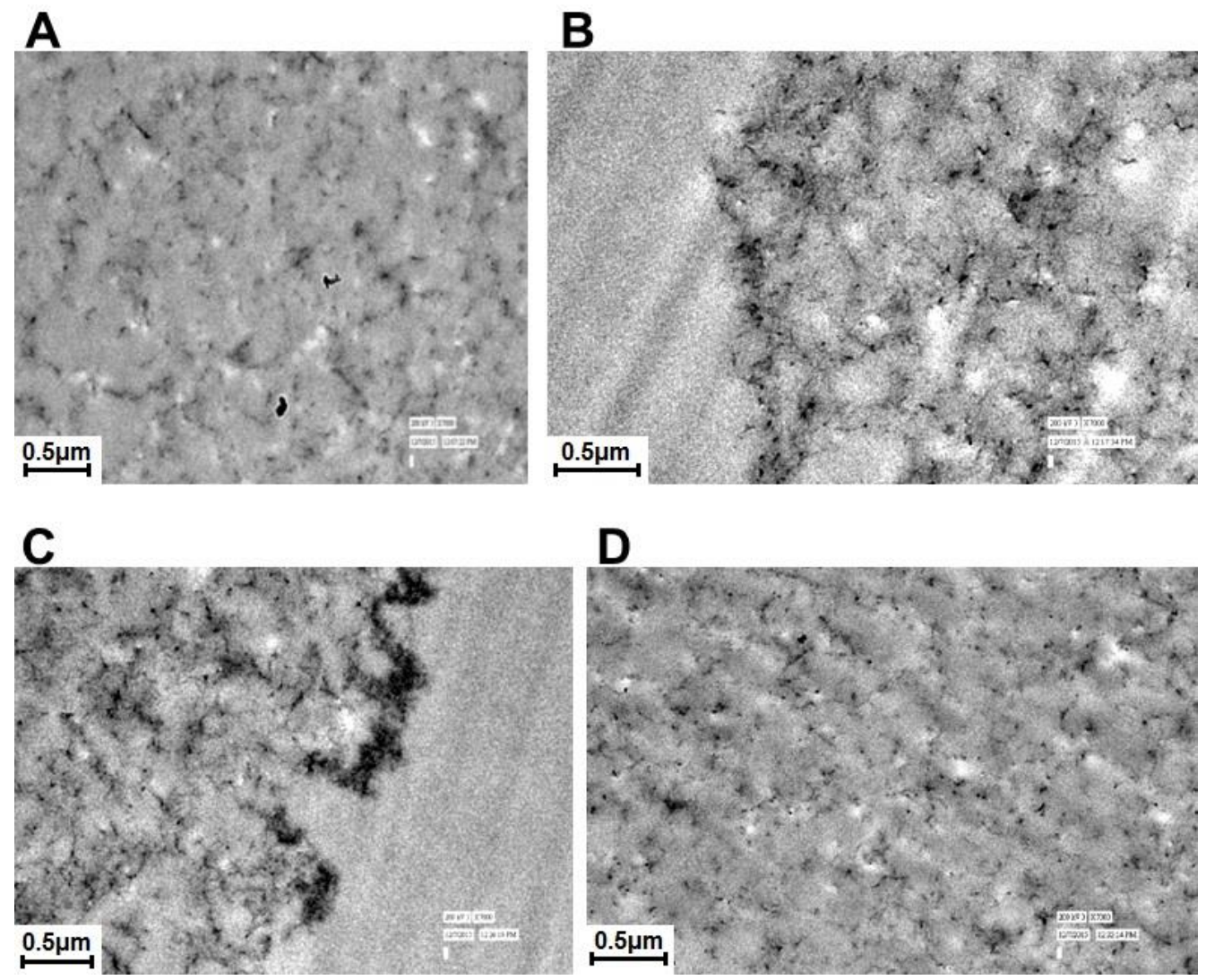
Figure 4: TEM imaging for fresh and fouled resin samples. (A) Fresh resin. (B) 50 cycles. (C) 100 cycles. (D) 100 cycles without feed material.

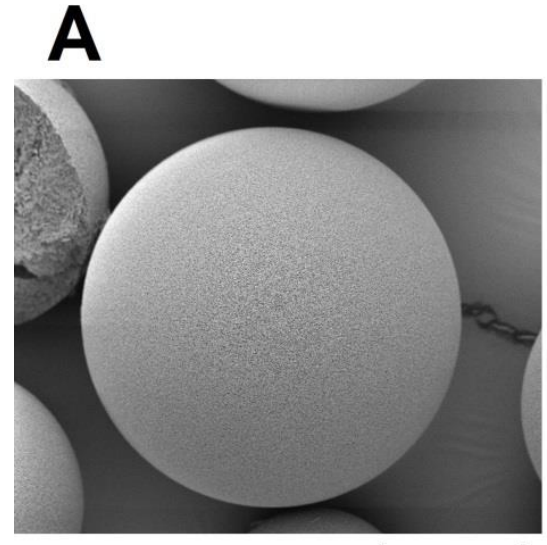

$\overleftarrow{40 \mu \mathrm{m}}$

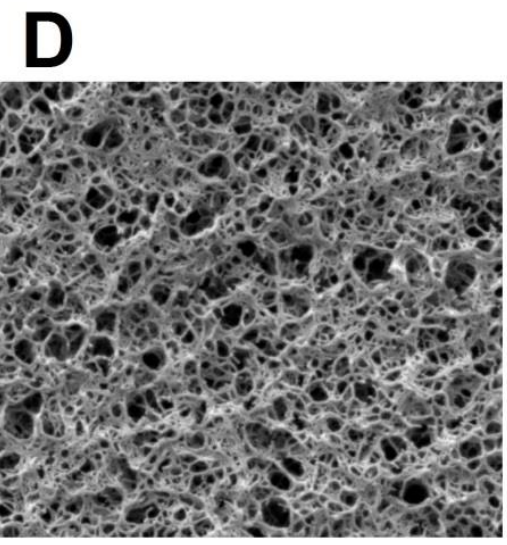

$1 \mu \mathrm{m}$
B

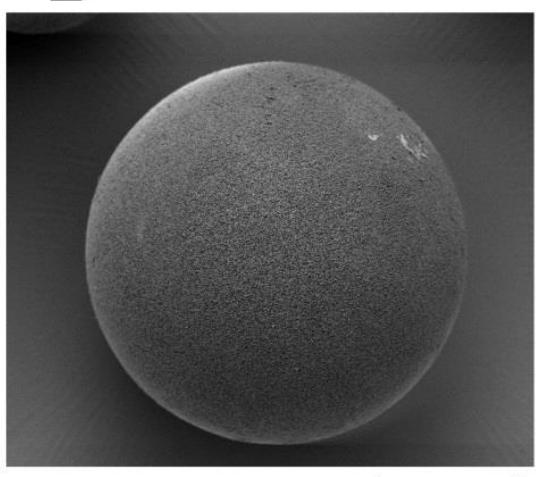

40um

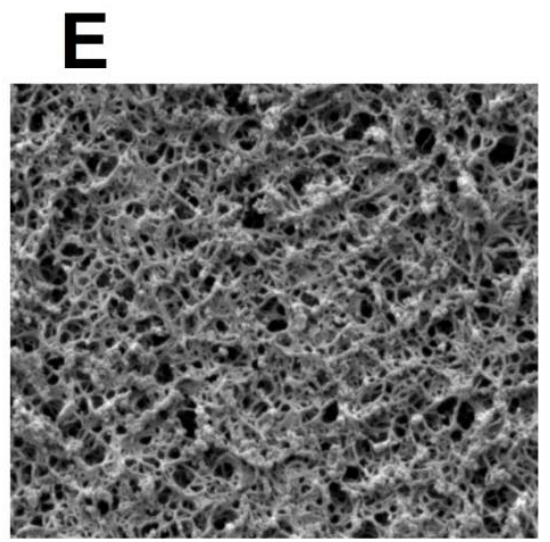

$1 \mu \mathrm{m}$
C

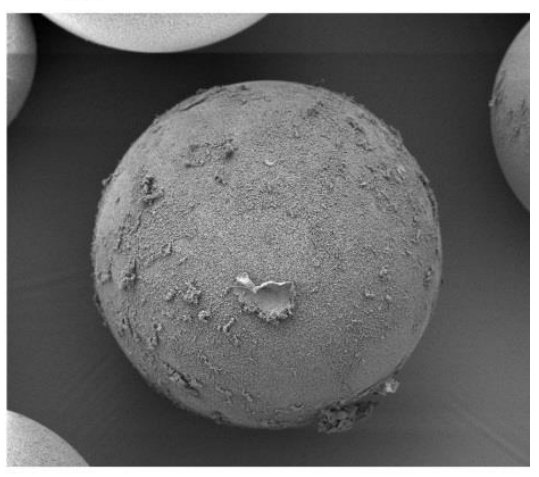

$40 \mu \mathrm{m}$

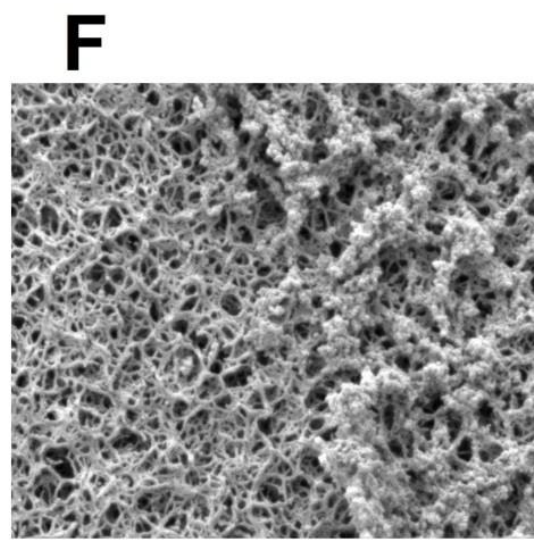

$1 \mu \mathrm{m}$

Figure 5: Electron micrographs of used chromatography beads at overall bead and detailed structure magnifications. (A) and (D) Resin that has not been cycled with feed material. (B) and (E) 50 cycles with feed material. (G) and (H) 100 cycles with feed material. 


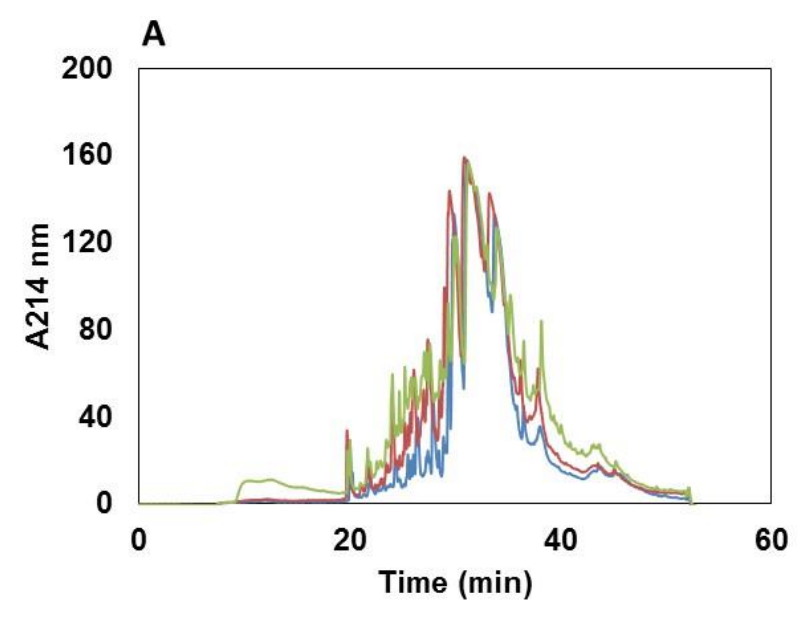

-Without load - Cycle $50-$ Cycle 100

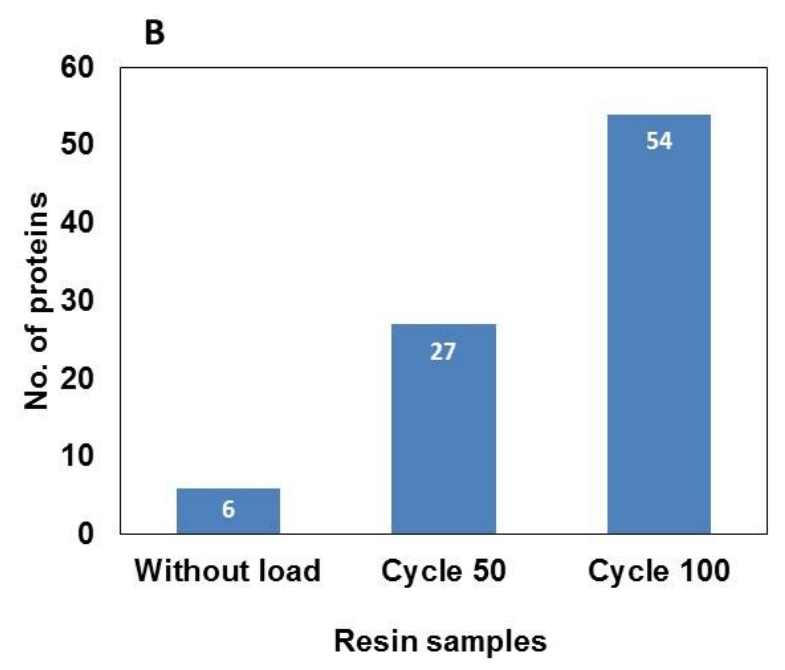

Figure 6: LC-MS/MS analysis to study the effect of resin fouling due to use of feed material and processing buffers.

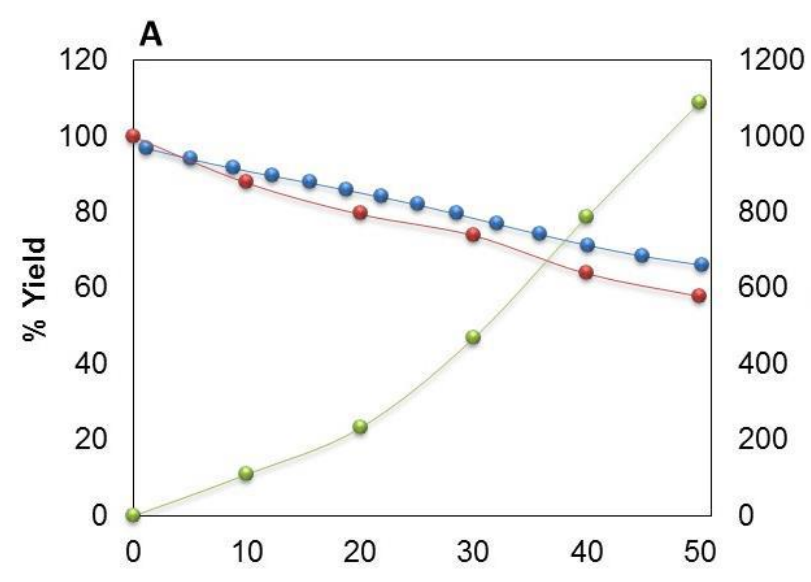

Cycle No.

- Yield $-\%$ DBC - Fluorescence

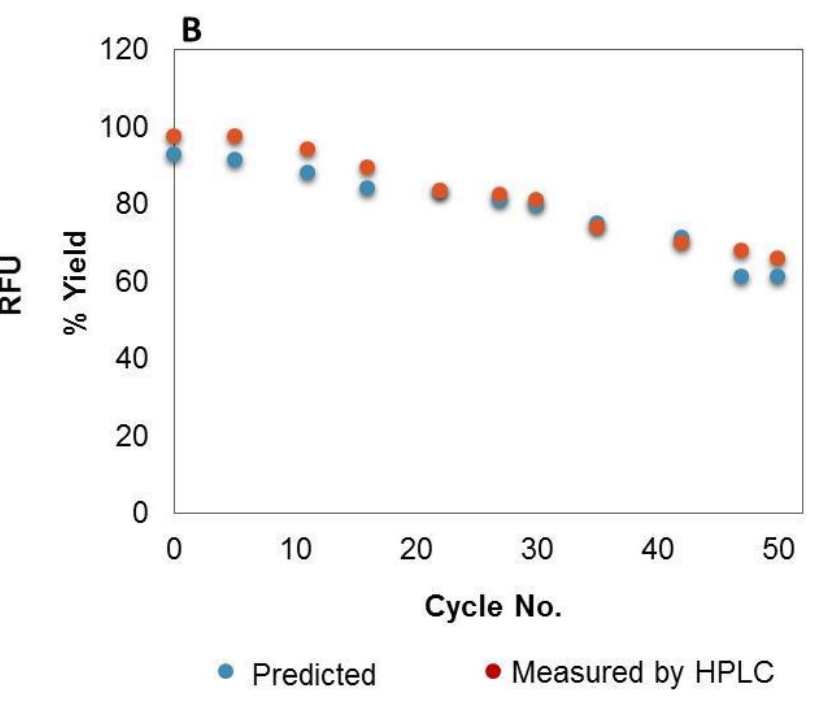

Figure 7: (A) Yield, $\mathrm{DBC}_{10 \%}$ and fluorescence intensity at $340 \mathrm{~nm}$ for 50 cycles. (B) Experimental and model predicted yield data for 50 cycles. 
Table 1: Summary of methods used by researchers to determine protein A chromatography performance decay

\begin{tabular}{lcc} 
Methods & $\begin{array}{c}\text { Direct/ Indirect measurement of } \\
\text { resin fouling }\end{array}$ & Reference \\
\hline Static binding capacity & Indirect & 16,19 \\
Dynamic binding capacity & Indirect & 20,26 \\
HETP & Indirect & 19,20 \\
Elution peak profile & Indirect & 21 \\
LC-MS/MS & Indirect & $27,29,30$ \\
2D PAGE & Indirect & 28 \\
TEM and SEM & Direct & 31,32 \\
CLSM & Direct & $31,32,33$, \\
& & 34 \\
Magnetic resonance imaging and & Direct & 35,36 \\
X-ray computed tomography & & \\
FTIR & Direct & 25,37 \\
HCP, HCD and LPA analysis & Indirect & 20 \\
Particle size measurement & Direct & 17,20 \\
Particle porosity & Indirect & 20 \\
\hline
\end{tabular}

Table 2: Summary of attributes measured for fresh and fouled resin

\begin{tabular}{lcccc}
\hline \multicolumn{1}{c}{ Attributes measured } & Fresh resin & $\begin{array}{c}\text { Without load 100 } \\
\text { cycles }\end{array}$ & $\begin{array}{c}\text { With load 50 } \\
\text { cycles }\end{array}$ & $\begin{array}{c}\text { With load } \\
\mathbf{1 0 0} \text { cycles }\end{array}$ \\
\hline Yield $(\%)$ & $100 \%$ & NA & $77 \%$ & $70 \%$ \\
DBC $(\%)$ & $100 \%$ & $85 \%$ & $60 \%$ & $20 \%$ \\
Inter particle porosity & $\sim 0.45$ & $\sim 0.45$ & $\sim 0.45$ & $\sim 0.45$ \\
Intra particle porosity & 0.95 & 0.93 & 0.87 & 0.66 \\
Particle size $(\mu \mathrm{m})$ & 85 & 83 & NA & 82 \\
\hline
\end{tabular}


Table 3: Comparison of different analytical tools to measure resin fouling

\begin{tabular}{|c|c|c|c|c|c|}
\hline $\begin{array}{l}\text { Tools/ } \\
\text { parameters }\end{array}$ & $\begin{array}{c}\text { Direct/ } \\
\text { Indirect } \\
\text { measureme } \\
\text { nt of resin } \\
\text { fouling }\end{array}$ & $\begin{array}{l}\text { Mode of } \\
\text { analysis }\end{array}$ & $\begin{array}{ll}\text { Sample } & \text { Analysi } \\
\text { preparati } & \text { s time } \\
\text { on time } & \end{array}$ & $\begin{array}{l}\text { Feasibilit } \\
\text { y of } \\
\text { online/ } \\
\text { atline/ } \\
\text { offline }\end{array}$ & Remarks \\
\hline$\%$ Yield & Indirect & Quantitative & $\begin{array}{l}5 \text { min (Can be done } \\
\text { at every cycle) }\end{array}$ & Atline & $\begin{array}{l}\text { Measured by } \\
\text { UV 280nm for } \\
\text { atline. }\end{array}$ \\
\hline$\% \mathrm{DBC}$ & Indirect & Quantitative & 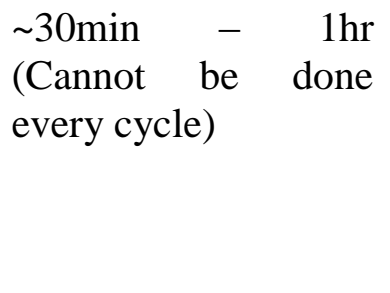 & Offline & $\begin{array}{l}\text { Separate } \\
\text { experiments } \\
\text { are carried out } \\
\text { to determine } \\
\text { DBC at certain } \\
\text { cycles }\end{array}$ \\
\hline Porosity & Indirect & Quantitative & $\begin{array}{l}\text { 15-30 min (Cannot } \\
\text { be done every cycle) }\end{array}$ & Offline & $\begin{array}{l}\text { Separate } \\
\text { experiments } \\
\text { carried out to } \\
\text { measure } \\
\text { porosity at } \\
\text { certain cycles }\end{array}$ \\
\hline $\begin{array}{l}\mathrm{HCP} / \mathrm{HCD} / \\
\text { Leachate }\end{array}$ & Indirect & Quantitative & $\sim 2 \mathrm{hr}$ & Offline & $\begin{array}{l}\text { Elute samples } \\
\text { are analyzed } \\
\text { by kit based } \\
\text { methods }\end{array}$ \\
\hline Particle size & Direct & Qualitative & $\sim 15$ min & Offline & $\begin{array}{l}\text { Resin sample } \\
\text { is withdrawn } \\
\text { from column } \\
\text { and analyzed } \\
\text { by mastersizer }\end{array}$ \\
\hline FTIR & Direct & Quantitative & & Offline & $\begin{array}{l}\text { Resin sample } \\
\text { is withdrawn } \\
\text { from column } \\
\text { and analyzed } \\
\text { by FTIR }\end{array}$ \\
\hline LC-MS/MS & Indirect & Qualitative & & Offline & $\begin{array}{l}\text { Resin sample } \\
\text { is withdrawn } \\
\text { from column } \\
\text { are digested } \\
\text { and analyzed } \\
\text { for presence of } \\
\text { foulants }\end{array}$ \\
\hline Fluorescence & Direct & Quantitative & $<5 \min$ & Online & $\begin{array}{l}\text { Analyzed } \\
\text { online with } \\
\text { developed tool }\end{array}$ \\
\hline
\end{tabular}




\begin{tabular}{|c|c|c|c|c|c|c|}
\hline & & & & & & $\begin{array}{l}\text { without } \\
\text { hampering the } \\
\text { chromatograph } \\
\text { y runs }\end{array}$ \\
\hline TEM & Direct & Qualitative & $\sim 1$ day & $\begin{array}{l}\sim 15-30 \\
\min \end{array}$ & Offline & $\begin{array}{l}\text { Resin sample } \\
\text { is withdrawn } \\
\text { from column } \\
\text { are subjected } \\
\text { to sample } \\
\text { preparation }\end{array}$ \\
\hline SEM & Direct & Qualitative & & & Offline & \\
\hline
\end{tabular}

